\title{
Impact of lignin polymer backbone esters on ionic liquid pretreatment of poplar
}

\author{
Kwang Ho Kim,2, Tanmoy Dutta1,2, John Ralph 3,4, Shawn D. Mansfield ${ }^{4,5}$, Blake A. Simmons ${ }^{1,6}$ \\ and Seema Singh ${ }^{1,2^{*}}$
}

\begin{abstract}
Background: Biomass pretreatment remains an essential step in lignocellulosic biofuel production, largely to facilitate the efficient removal of lignin and increase enzyme accessibility to the polysaccharides. In recent years, there have been significant efforts in planta to reduce lignin content or modify its composition to overcome the inherent recalcitrance that it imposes on lignocellulosic biomass during processing. Here, transgenic poplar lines in which monolignol ferulate conjugates were synthesized during cell wall development to introduce, during lignification, readily cleavable ester linkages into the lignin polymer backbone (i.e.,"zip lignin"), along with wild-type (WT) controls, were pretreated with different ionic liquids (ILs).

Results: The strategic introduction of ester bonds into the lignin backbone resulted in increased pretreatment efficiency and released more carbohydrates with lower energy input. After pretreatment with any of three different ILs, and after limited saccharification, the transgenic poplars, especially those with relatively higher amounts of incorporated monolignol ferulate conjugates, yielded up to $23 \%$ higher sugar levels compared to WT plants.

Conclusion: Our findings clearly demonstrate that the introduction of ester linkages into the lignin polymer backbone decreases biomass recalcitrance in poplar has the potential to reduce the energy and/or amount of IL required for effective pretreatment, and could enable the development of an economically viable and sustainable biorefinery process.
\end{abstract}

Keywords: Biofuels, Biomass, Lignocellulose

\section{Background}

In recent years, lignocellulosic biomass has received a significant attention as a renewable resource to reduce societal dependence on fossil fuels. It is estimated that there are over one billion tons of biomass available annually in the United States alone for conversion into biofuels and renewable chemicals [1, 2]. Moreover, the adoption of near-term technologies, such as cellulosic ethanol, could effectively reduce net automotive greenhouse gas emissions [3]. From a techno-economical standpoint, however, the relatively high production cost of cellulosic ethanol has thus far limited its commercialization, compared to the less favorable but technically uncomplicated

\footnotetext{
*Correspondence: seesing@sandia.gov

${ }^{2}$ Biological and Engineering Sciences Center, Sandia National

Laboratories, 7011 East Avenue, Livermore, CA 94551, USA

Full list of author information is available at the end of the article
}

first-generation ethanol from cane sugar or corn grain starch. In the biomass-to-ethanol process, pretreatment has consistently been highlighted as one of the most expensive unit operations, which has largely been attributed to the recalcitrance of the lignocellulosic cell wall structure. Among the three biomass components, the lignin polymer acts as the major impediment to bioethanol processing [4].

There have been many efforts to redesign lignin to render it more amenable to chemical depolymerization, which can lower the energy required for industrial processing [4-7]. For example, switchgrass recalcitrance has been reduced by downregulating the caffeic acid 3-O-methyltransferase (COMT) gene in the lignin pathway; a reduced lignin content and altered lignin composition led to increases in saccharification efficiency, requiring less severe pretreatment and lower enzyme 
loading to achieve the same ethanol yield [7]. Similarly, poplars downregulated in cinnamoyl-CoA reductase $(C C R)$ had more facile saccharification but at a biomass yield penalty [8]. A selective reduction in lignin and increase in cellulose accumulation was shown to impact the secondary cell wall structure in Arabidopsis [9]. Recently, with the basic idea of introducing readily cleavable bonds into the lignin backbone to lower the energy requirement for biomass processing, poplar was engineered to produce monolignol ferulate conjugates to augment the monomer pool by introducing an exotic feruloyl-CoA monolignol transferase (FMT) genes [4]. The resultant generation of lignin polymer backbone chains containing ester linkages improved cell wall digestibility, liberated more sugars after pretreatment, and improved saccharification compared to the WT [4].

Among the different pretreatment approaches, certain ILs have shown considerable promise as efficient and effective solvents for biomass pretreatment. ILs are molten organic salts composed of ions, and most of them exist in the liquid state below $100{ }^{\circ} \mathrm{C}$ [10]. Moreover, pretreatments employing ILs can occur under milder conditions, and ILs can be recycled and reused after biomass processing [11]. IL pretreatment can preferentially remove lignin and convert microcrystalline cellulose to its non-crystalline allomorph [12-14]. For example, 1-ethyl-3-methylimidazolium acetate $\left(\left[\mathrm{C}_{2} \mathrm{C}_{1} \mathrm{Im}\right][\mathrm{OAc}]\right)$ has been found to completely dissolve biomass under specific pretreatment conditions, providing a promising platform to separate the biomass components [2]. Recently, ILs containing choline cations and amino acid anions $[\mathrm{Ch}][\mathrm{AA}]$, coined "bionic liquids", have been shown to selectively remove lignins, resulting in high sugar yields [15-17]. Along with their lignin dissolving efficiencies, bionic liquids have gained significant favor because of their biocompatibility with enzymes and even with microorganisms, especially when compared to imidazolium-based ILs [15], opening up the possibility of a one-pot process for ethanol production [18]. Pretreatment efficiency studies employing imidazolium- and choline-based ILs found that [Lys] ${ }^{-}$anions could provide greater delignification and higher glucose yields than ILs containing [OAc] $^{-}$anions [15]. In addition to the bionic liquids, recent development of a highly effective pretreatment process utilizing the aqueous IL composed of tetrabutylammonium and hydroxide ions ([TBA] $[\mathrm{OH}])$ generated high glucose yields after pretreatment under mild conditions $\left(50{ }^{\circ} \mathrm{C}\right)[19]$. The $[\mathrm{TBA}][\mathrm{OH}] \mathrm{IL}$ was found to have higher ionic mobility, enhancing the removal of lignin and noncellulosic components of biomass under mild pretreatment conditions [19].

We have previously reported on the development of IL pretreatment processes using various ILs [2, 15, 19-21].
Herein, we demonstrate that utility of ILs for pretreating transgenic poplar whose lignin was designed for improved deconstructability by introducing chemically labile esters into the lignin backbone. We show that the transgenic poplar required less severe pretreatment and can be processed more readily to liberate significantly more sugar monomers under milder pretreatment conditions.

\section{Methods}

\section{Raw materials}

Transgenic poplar (Populus alba $\times$ grandidentata) that was originally developed and grown at the University of British Columbia, Vancouver, BC, Canada, was provided by the Great Lakes Bioenergy Research Center (GLBRC) [4]. Briefly, hybrid poplar transformed with an exogenous feruloyl-CoA monolignol transferase (FMT) that catalyzes the formation of monolignol ferulates that ultimately get incorporated into the lignin polymer during lignification were used for all experiments. The details, including gene identification and expression analysis (FMT), plant growth, and compositional analysis, have been previously described [4]. Both transgenic and WT poplars were ground and sieved to a constant size of 1-3 mm prior to pretreatment. 1-Ethyl-3-methylimidazolium acetate $\left[\mathrm{C}_{2} \mathrm{C}_{1} \mathrm{Im}\right][\mathrm{OAc}]$ was purchased from BASF (Florham Park, $\mathrm{NJ})$ and used as received. Cholinium lysinate [Ch] [Lys] and tetrabutylammonium hydroxide $[\mathrm{TBA}][\mathrm{OH}]$ were purchased from Iolitec (Tuscaloosa, AL) and used as received. The commercial cellulase mixture $\left(\mathrm{Cellic}^{\circledR} \mathrm{CTec} 2\right)$ and hemicellulase mixture $\left(\right.$ Cellic $^{\circledR}$ HTec2) were generously provided by Novozymes (Davis, CA) and used as received. Compositional analysis of raw materials and pretreated poplar samples was conducted using a National Renewable Energy Laboratory (NREL) protocol [22].

\section{Biomass pretreatment and saccharification}

A $10 \mathrm{wt} \%$ biomass solution was carefully prepared by combining $0.2 \mathrm{~g}$ (dry weight) of biomass with $1.8 \mathrm{~g}$ of one of three ILs in a $10 \mathrm{~mL}$ pressure tube (Ace Glass, Vineland, NJ). The tubes, in triplicate, were heated in an oil bath to a predetermined temperature with continuous stirring (Table 1). After pretreatment, $6 \mathrm{~mL}$ of deionized (DI) water was added to the reaction slurry, and the mixture transferred to $50 \mathrm{~mL}$ Falcon tube that was then centrifuged at $1000 \mathrm{rpm}$ to separate the lignin from the supernatant containing the ILs. The pelleted precipitates, mainly polysaccharides, were then washed four times with $6 \mathrm{~mL}$ of DI water $(4 \times 6 \mathrm{~mL})$ to remove any residual IL.

Enzymatic saccharification of the pretreated biomass was conducted for $72 \mathrm{~h}$ in $5 \mathrm{~mL}$ of $50 \mathrm{mM}$ sodium citrate buffer ( $\mathrm{pH}$ 4.8) supplemented with Cellic ${ }^{\circledR} \mathrm{CTec} 2$ and 
Table 1 lonic liquids used in this study, and pretreatment conditions studied

ILs Structure \begin{tabular}{l}
$\begin{array}{l}\text { Pretreatment } \\
\text { conditions }\end{array}$ \\
\hline$\left[\mathrm{C}_{2} \mathrm{C}_{1} \mathrm{Im}\right]$
\end{tabular}

HTec2 $(188 \mathrm{mg} / \mathrm{mL})$ from Novozymes (9:1 ratio) at $10 \mathrm{mg}$ protein/gram solid biomass of, at $50{ }^{\circ} \mathrm{C}$ and $150 \mathrm{rpm}$ in a rotary incubator.

\section{Analytical methods}

After pretreatment and saccharification, the hydrolysate was separated from the residual substrate by centrifugation, and then filtered through a $0.45 \mu \mathrm{m}$ syringe filter. Glucose and xylose release was quantified using an Agilent 1100 series high-performance liquid chromatograph (HPLC) equipped with a Bio-Rad Aminex HPX-87H ion-exchange column and a refractive index (RI) detector. The mobile phase employed to achieve separation was $4 \mathrm{mM} \mathrm{H}_{2} \mathrm{SO}_{4}$ at a constant flow rate of $0.6 \mathrm{~mL} / \mathrm{min}$ and the column temperature was maintained at $60{ }^{\circ} \mathrm{C}$. The yield of glucose and xylose was determined after subtracting their levels in an enzyme blank.

Gel-permeation chromatography (GPC) was used to determine the relative molecular weight distribution of the lignin-rich residue after enzymatic saccharification. GPC measurements were carried out using a Tosoh Ecosec HLC-8320 GPC equipped with a UV detector, whose wavelength was set at $280 \mathrm{~nm}$. The eluent for the analysis was tetrahydrofuran and the column used was an Agilent PLgel $3 \mu \mathrm{m} 100 \AA(300 \times 7.5 \mathrm{~mm})$. The column flow rate was $1.0 \mathrm{~mL} \mathrm{~min}{ }^{-1}$ at $35^{\circ} \mathrm{C}$. Polystyrene standards were purchased from Agilent (Agilent Technologies, Inc., Santa Clara, CA) and used to establish a calibration curve that ranged from 162 to $29,150 \mathrm{~g} \mathrm{~mol}^{-1}$. All samples were derivatized using acetic acid and acetyl bromide (92:8, $\mathrm{v} / \mathrm{v}$ ) for $2 \mathrm{~h}$ at $60^{\circ} \mathrm{C}$ prior to GPC analysis [23].

Raw biomass and residual solids from WT and transgenic Line 5 after IL pretreatment were ball-milled, solubilized in 4:1 DMSO- $d_{6} /$ pyridine- $d_{5}$, and then analyzed by two-dimensional (2D) ${ }^{1} \mathrm{H}-{ }^{13} \mathrm{C}$ heteronuclear singlequantum coherence (HSQC) nuclear magnetic resonance (NMR) spectroscopy as previously described [24, 25]. In short, samples were ball-milled using a Fritsch Pulverisette 7 and approximately $50 \mathrm{mg}$ were placed in NMR tubes with $600 \mu \mathrm{L}$ DMSO- $d_{6} /$ pyridine- $d_{5}$. The samples were sealed and sonicated until homogeneity in a Branson 2510 table-top cleaner (Branson Ultrasonic Corporation, Danbury, CT). The temperature of the bath was closely monitored and maintained below $55{ }^{\circ} \mathrm{C}$. HSQC spectra were acquired at $25{ }^{\circ} \mathrm{C}$ using a Bruker Avance-600 MHz instrument equipped with a $5 \mathrm{~mm}$ inverse gradient ${ }^{1} \mathrm{H} /{ }^{13} \mathrm{C}$ cryoprobe using the "hsqcetgpsisp2.2" pulse program ( $\mathrm{ns}=200, \mathrm{ds}=16$, number of increments $=256, \mathrm{~d} 1=1.0 \mathrm{~s})$. Chemical shifts were referenced to the central DMSO peak $\left(\delta_{\mathrm{C}} / \delta_{\mathrm{H}} 39.5 / 2.5 \mathrm{ppm}\right)$. Assignment of the HSQC spectra is described elsewhere $[24,26]$. Changes in lignin structural characteristics were determined based on volume integration of HSQC spectral contour correlations using the Bruker's Topspin 3.1 processing software.

\section{Statistical analysis}

Analysis of variance (ANOVA) was conducted using R ( R Foundation for Statistical Computing, Vienna, Austria) to test the null hypothesis of no statistical differences in saccharification yield between the WT and transgenic FMT poplar. Triplicate samples were collected for each transgenic line and the corresponding control trees. The null hypothesis was rejected at the 0.05 level.

\section{Results}

Pretreatment of poplar with cholinium lysinate ([Ch][Lys])

Pretreatment of transgenic poplar with [Ch][Lys] was carried out at $140{ }^{\circ} \mathrm{C}$ for $1 \mathrm{~h}$, a pretreatment condition previously determined to be optimal for switchgrass [15]. The pretreated substrates were then hydrolyzed using commercial enzymes, at $50{ }^{\circ} \mathrm{C}$ and a $\mathrm{pH}$ of 4.8 . As shown in Fig. 1, significant increases in saccharification yield after [Ch][Lys] pretreatment were apparent in some transgenic poplar lines, especially Lines 5 and 6 . Under these conditions, the yield of glucose (on a dry initial biomass basis) released from WT was $29.5 \%$, whereas $36.4 \%$ (23.4\% higher) glucose was liberated from Line 5. The amount of ML-FA conjugate incorporated during poplar lignification can only be crudely estimated from the low release of diagnostic conjugates [4, 27], but digestibility is hypothesized to be associated with the level of ML-FA conjugate in the lignin. The trend observed in the digestibility efficiency in this study is consistent with previous saccharification results that used mild alkaline pretreatments [4]. Compared to mild alkaline pretreatment, however, the overall glucose yield was increased 


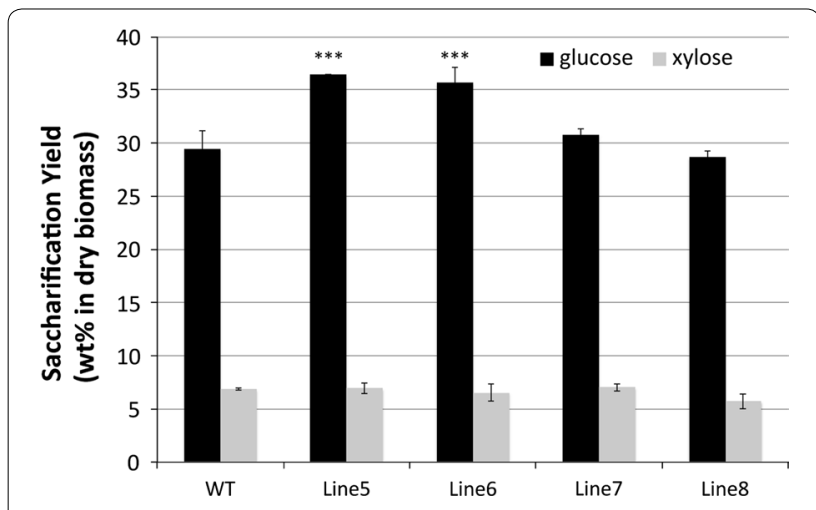

Fig. 1 Saccharification yield (wt\% based on initial dry biomass) from the [Ch] [Lys] pretreated WT and transgenic poplars (statistical significance from $W T{ }^{* * *} P<0.001 ;{ }^{* *} P<0.01 ;{ }^{*} P<0.05$ )

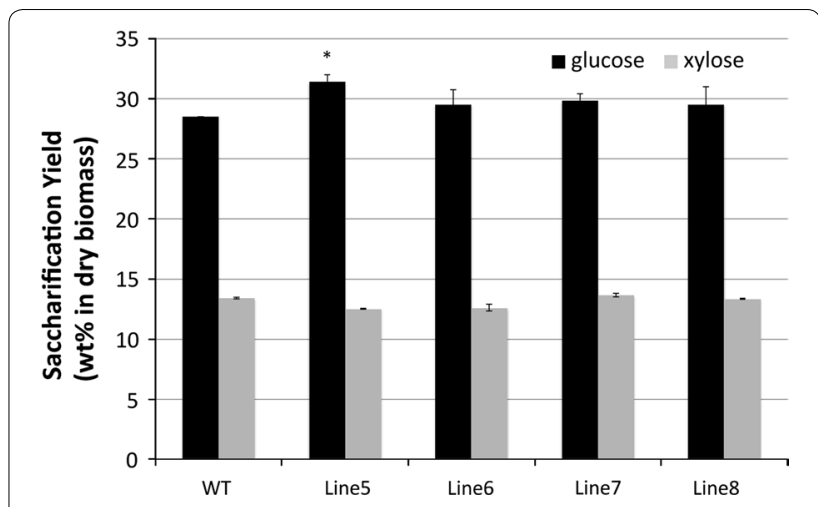

Fig. 2 Saccharification yield (wt\% based on initial dry biomass) from the $\left[\mathrm{C}_{2} \mathrm{C}_{1} \mathrm{Im}\right][\mathrm{OAc}]$ pretreated WT and transgenic poplars (statistical significance from $W{ }^{* * *} P<0.001 ; * * P<0.01 ; * P<0.05$ ) approximately $40 \%$ when pretreated with [Ch][Lys]. The higher sugar yield is likely associated with the performance of [Ch][Lys] as a pretreatment. The strategic introduction of ester bonds into the lignin backbone did not affect xylose yield, likely due to the poor xylan recovery after pretreatment [15]. As shown in the mass balance analysis (see Additional file 1), only $52-61 \%$ of xylan was actually recovered.

\section{Pretreatment of poplar with 1-ethyl-3-methylimidazolium} acetate $\left(\left[\mathrm{C}_{2} \mathrm{C}_{1} \mathrm{Im}\right][\mathrm{OAc}]\right)$

Imidazolium-based ILs, such as $\left[\mathrm{C}_{2} \mathrm{C}_{1} \mathrm{Im}\right][\mathrm{OAc}]$, have been recently evaluated for their use in pretreatment processes. It was clearly shown that $\left[\mathrm{C}_{2} \mathrm{C}_{1} \mathrm{Im}\right][\mathrm{OAc}] \mathrm{can}$ effectively solubilize plant cell wall components, which then allows selective precipitation of cellulose by adding an anti-solvent, leaving a large fraction of the lignin in solution [28], and results in a readily hydrolysable polysaccharide fraction. Figure 2 shows the sugar yields after $\left[C_{2} C_{1} \operatorname{Im}\right][\mathrm{OAc}]$ pretreatment followed by enzymatic hydrolysis. Again, the transgenic poplar lines yielded higher glucose. Among the transgenic lines, Line 5 showed the highest glucose yield, $10 \%$ higher than that of the WT poplar. Although the overall glucose yields are lower than those derived from the [Ch][Lys] pretreatment process, they were again higher for the transgenic poplar, which had a lower lignin content after pretreatment (see Additional file 1 for mass balance analysis). However, when the samples were pretreated with $\left[\mathrm{C}_{2} \mathrm{C}_{1} \operatorname{Im}\right][\mathrm{OAc}]$, most of the xylan $(>90 \%)$ was recovered, resulting in high xylose yields (which were not significantly different) after subsequent saccharification.

\section{Pretreatment of poplar with tetrabutylammonium hydroxide ([TBA][OH])}

Although $\left[\mathrm{C}_{2} \mathrm{C}_{1} \mathrm{Im}\right][\mathrm{OAc}]$ shows significant cellulose dissolution, the IL and its solutions are relatively viscous and, therefore, require longer reaction times to dissolve the cellulosic fraction. Moreover, it is hard to handle, and even a small amount of water can cause a significant decrease in the cellulose solubility [29]. Recently, onium hydroxide solutions with water have been confirmed to dissolve cellulose at room temperature [30]. A hydrated IL $[\mathrm{TBA}][\mathrm{OH}]$, with properties suggesting that it could be useful as a next-generation solvent for biomass pretreatment, was, therefore, also used to determine how well the cell walls containing the conjugates could be processed under mild conditions. Figure 3 shows the sugar yields from the $[\mathrm{TBA}][\mathrm{OH}]$-pretreated poplars. The glucose yields were again statistically higher with wood derived from the transgenic poplars (Lines 5, 6, and 7) than those from the corresponding WT. Similar to other IL pretreatments, transgenic Line 5 produced the highest glucose yield, approximately $17.7 \%$ higher than WT. However, the yields of xylose were less than 3\% for all samples. As the mass balance analysis shows, less than $20 \%$ of the xylan was recovered after pretreatment.

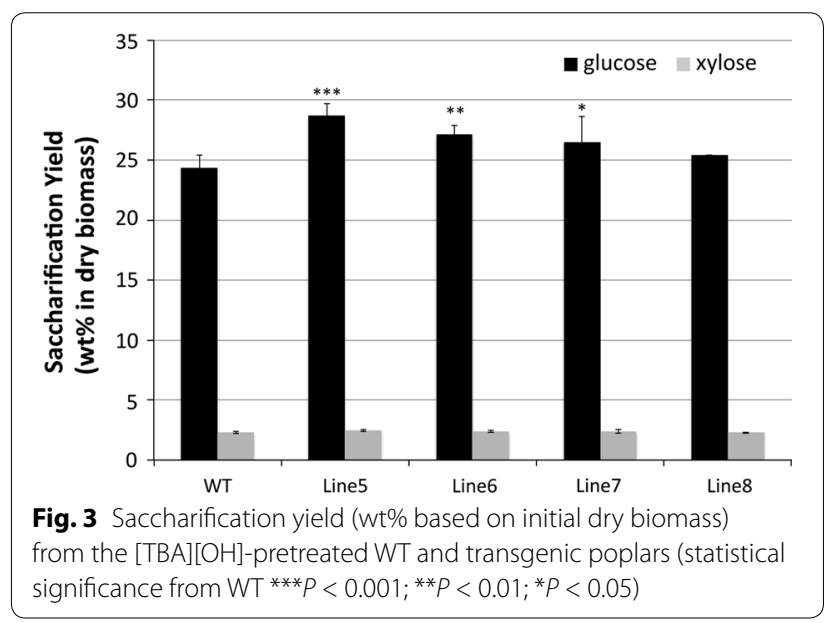




\section{Impact of plant cell wall modification on pretreatment severity}

It is clear that the transgenic poplar lines examined herein release more carbohydrates than the corresponding WT biomass when pretreated with any of the ILs tested. The use of [Ch][Lys] resulted in the best yields among the three ILs evaluated. It was logically hypothesized that the reduced recalcitrance of the transgenic poplar would facilitate the release of significantly more monosaccharides after pretreatments under lower severity conditions. To test this hypothesis, WT and the best overall performing transgenic line (Line 5) were pretreated with $[\mathrm{Ch}][\mathrm{Lys}]$ at $100{ }^{\circ} \mathrm{C}$. Under these conditions, Line 5 yielded $31.8 \%$ glucose versus only $25.4 \%$ from WT (Fig. 4). Although the yields were lower than those from pretreatments at $140{ }^{\circ} \mathrm{C}$, the transgenic poplar again showed a significant increase in glucose release. This clearly demonstrates that employing trees with designer lignin can indeed decrease the inherent recalcitrance of biomass and has the potential to reduce the energy required for effective pretreatment.

\section{HSQC analysis of structural changes to lignin (and polysaccharides) during pretreatment}

The starting biomass and the corresponding IL-pretreated biomass were subjected to HSQC-NMR analyses to elucidate the effects of IL pretreatment on cell wall structure. The HSQC spectra, respective peak assignments, and substructures of WT and transgenic Line 5 are shown in Fig. 5. There were no distinct differences in the relative content of prominent lignin units, with their characteristic interunit linkages, or S/G ratios between the samples. The HSQC spectra can be divided broadly into well-resolved aromatic $\left(\delta_{\mathrm{H}} / \delta_{\mathrm{C}} 6.0-8.0 / 90-160\right)$ and aliphatic $\left(\delta_{\mathrm{H}} / \delta_{\mathrm{C}} 2.5-6.0 / 50-90\right)$ regions that contain the carbohydrate and lignin (oxygenated) aliphatic signals.

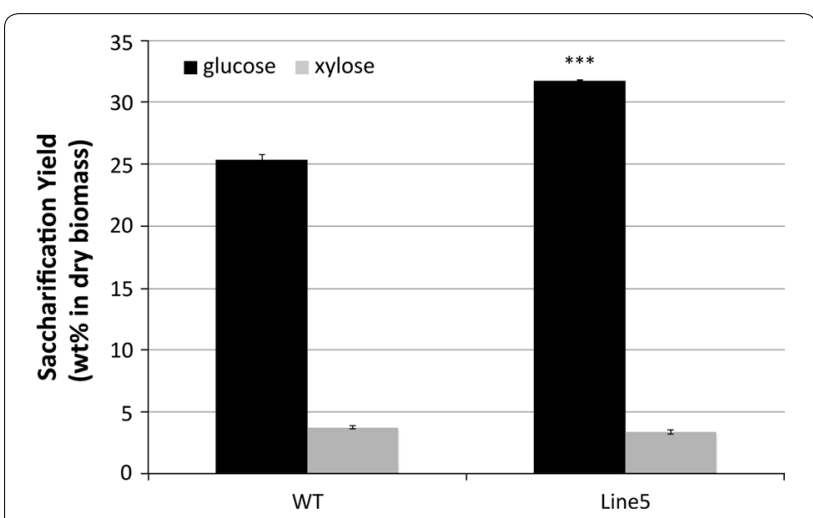

Fig. 4 Saccharification yield (wt\% based on initial dry biomass) from the [Ch] [Lys] pretreated WT and transgenic Line 5 at $100{ }^{\circ} \mathrm{C}$ (statistical significance from $\left.W T{ }^{* * *} P<0.001 ;{ }^{* *} P<0.01 ;{ }^{*} P<0.05\right)$
The aliphatic region provides important information about the various types of lignin units, characterized by their various interunit linkages. All HSQC spectra of raw and IL-pretreated biomass showed correlations corresponding to all of the sidechain $\mathrm{C} / \mathrm{H}$ pairs for $\beta$-ether $\left(\beta-O-4^{\prime}\right.$, substructure $\left.\mathbf{A}\right)$, phenylcoumaran $\left(\beta-5^{\prime}\right.$, substructure $\mathbf{B})$, and resinol $\left(\beta-\beta^{\prime}\right.$, substructure $\left.\mathbf{C}\right)$ units. The relative amounts of each are estimated from the volume integrals of the $\mathbf{A}_{\alpha}, \mathbf{B}_{\alpha}$, and $\mathbf{C}_{\alpha}$ correlations, and expressed as a fraction of the total; the $\mathbf{C}$-unit integrals are divided by 2 , as a resinol unit contains two identical $\mathrm{C} / \mathrm{H}$ pairs per unit. As is normal for hardwood lignins, both the WT and transgenic poplars were found to be rich in $\beta$-ether units $\mathbf{A}$ with marginal amounts of $\beta-5^{\prime}$ and $\beta-\beta^{\prime}$ units, and as is also normal from $\mathrm{S}$-rich lignins, no signals were apparent from dibenzodioxocins that can result from the 5-5-coupling of G phenolic end-groups of oligomers [31].

The spectra of the pretreated biomass samples from the WT and transgenic poplars exhibit similar features for all three IL pretreatments. The $\beta-O-4^{\prime}$ content of both WT and transgenic poplar was found to be marginally (but probably not statistically significantly) lower than the respective untreated biomass for [Ch][Lys] and $[\mathrm{TBA}][\mathrm{OH}]$ pretreatments. The reduction in $\beta-O-4^{\prime}$ content, which is measured by the volume integral of $\mathbf{A}_{\alpha}$ correlation, may be a result of dehydration and the corresponding depolymerization that occurred during the pretreatment process.

The aromatic regions are dominated by the signals from the aromatic ring correlations from syringyl (S) units (derived from sinapyl alcohol) and guaiacyl (G) units (derived from coniferyl alcohol). $\mathrm{S}$ units show distinct signals from magnetically equivalent $\mathrm{C}_{2,6}-\mathrm{H}_{2,6}$ correlation, whereas $\mathrm{G}$ unit shows multiple signals corresponding to $\mathrm{C}_{2}-\mathrm{H}_{2}, \mathrm{C}_{5}-\mathrm{H}_{5}$, and $\mathrm{C}_{6}-\mathrm{H}_{6}$ correlations. Both the WT and transgenic poplar lignins are S-rich S-G lignins as in previously published results $[4,31,32]$. The $S / G$ ratio for the transgenic may be slightly higher than for the WT. No distinct signals from $p$-hydroxyphenyl $(\mathrm{H})$ units (derived from $p$-coumaryl alcohol) were observed at the shown contour level. Oxidized ( $\alpha$-ketone) structures from $S$ and $G$ units (i.e., $S^{\prime}$ and $G^{\prime}$ ) were identified in some of the samples. Apart from $S$ and $G$ units, signals from $p$-hydroxybenzoates (PB), unsaturated side-chains from cinnamaldehyde (J), and cinnamyl alcohol (I) endgroups (on $\mathrm{S}$ or $\mathrm{G}$ units) were also apparent. No signals corresponding to the monolignol ferulates that had been incorporated into the lignins could be observed in the transgenic samples, most probably because of the huge array of structures that can form, as noted in the supplementary information of the paper describing these transformed plants [4], and the consequent low abundance, below the NMR detection limit, of any such entities. 


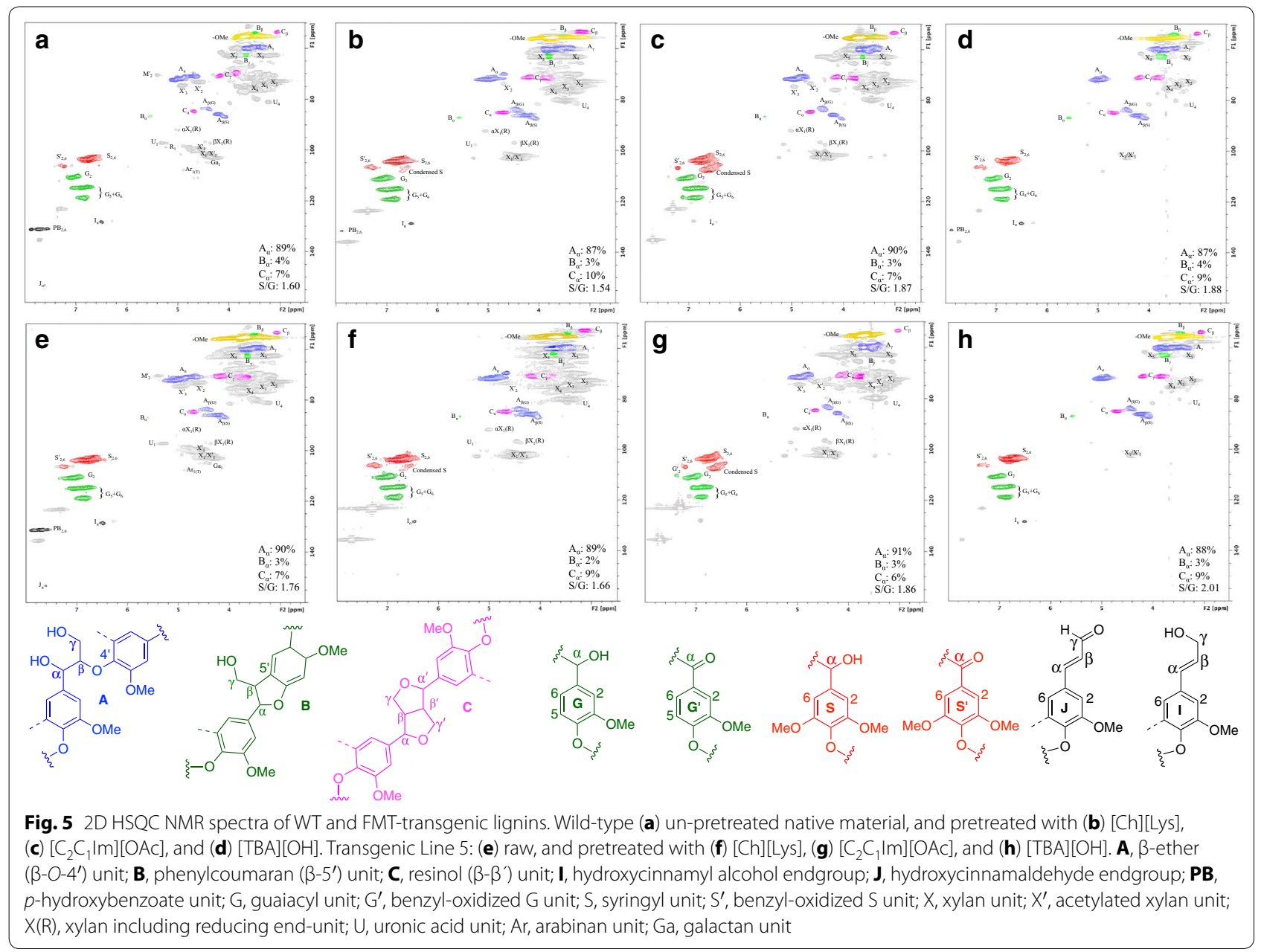

Indeed, in currently unpublished work, it is strikingly difficult to discern discrete correlation signals even in cell wall model systems in which 20,40 , and $60 \%$ coniferyl ferulates have been introduced into coniferyl alcohol lignification, except at the highest levels.

A decrease in the PB content, which is logical from the ease of cleaving this terminal aromatic ester, was observed for all pretreated biomass, along with a slight decrease in the cinnamaldehyde $\mathbf{J}$ and cinnamyl alcohol I end groups. No distinct differences in the changes in the S/G ratio were observed between WT and transgenic poplar when subject to all three IL pretreatments, and both types of biomass exhibit similar trends. A slight decrease in S/G ratio was observed for [Ch][Lys] pretreated poplar, whereas a slight increase in the $\mathrm{S} / \mathrm{G}$ ratio was observed for $\left[\mathrm{C}_{2} \mathrm{C}_{1} \mathrm{Im}\right][\mathrm{OAc}]$ and $[\mathrm{TBA}][\mathrm{OH}]$ pretreated poplar samples. The decrease in the $\mathrm{S} / \mathrm{G}$ ratio for [Ch] [Lys] pretreated poplar may be due to a loss of methoxyl units directly on S units, or to lignin depolymerization and subsequent dissolution into the IL. The [Ch] [Lys] and $\left[\mathrm{C}_{2} \mathrm{C}_{1} \mathrm{Im}\right][\mathrm{OAc}]$ pretreated poplars show signals corresponding to condensed S units, suggesting repolymerization reactions during the pretreatment.

The HSQC spectra also provided information on the polysaccharides present in the different samples. The anomeric region of the HSQC spectra contains the saccharide $\mathrm{C}_{1}-\mathrm{H}_{1}$ correlation signals. Different carbohydrate signals corresponding to xylans (e.g., $\mathrm{X} 1-\mathrm{X}^{\prime} 1, \alpha-\mathrm{X} 1[\mathrm{R}]$, and $\beta$-X1[R]), arabinans (Ar1[T]), galactans (Ga1), and glucuronic acid (U1) were also observed in this region of the HSQC spectra. In the aliphatic region, signals from $O$-acetylated xylans, namely, $3-O$-acetyl- $\beta$-Dxylopyranoside $\left(\mathrm{X}^{\prime} 3\right)$ and $2-O$-acetyl- $\beta$-D-xylopyranoside $\left(\mathrm{X}^{\prime} 2\right)$, can be clearly identified $[24,25]$.

The carbohydrate signals of the IL-pretreated biomass show some distinct differences. In the aliphatic region, the signals associated with two distinct peaks, $\mathrm{X}^{\prime} 2$ and $\mathrm{X}^{\prime} 3$, are significantly lower after $[\mathrm{Ch}][\mathrm{Lys}]$ and $\left[\mathrm{C}_{2} \mathrm{C}_{1} \mathrm{Im}\right]$ [OAc] pretreatment, and were absent after $[\mathrm{TBA}][\mathrm{OH}]$ pretreatment. These findings suggest that hemicellulose deacetylation occurs during IL pretreatment. The deacetylation behavior in the various ILs is intriguing; 
in [Ch][Lys], the X3-OAc appears to have been somewhat selectively removed (Fig. $5 \mathrm{~b}, \mathrm{f}$ ); in $\left[\mathrm{C}_{2} \mathrm{C}_{1} \mathrm{Im}\right][\mathrm{OAc}]$, both are moderately well retained (Fig. $5 \mathrm{c}, \mathrm{g}$ ); and in [TBA] $[\mathrm{OH}]$, complete xylan deacetylation has occurred (Fig. 5d, h). The anomeric regions of both biomasses also show noticeable decreases in the signals associated with of $\alpha-\mathrm{X} 1(\mathrm{R}) / \beta-\mathrm{X} 1(\mathrm{R})$ that may be ascribed to glycosidic bond cleavage and reductions in the degree of polymerization (DP) of hemicellulose during IL pretreatment. Signals corresponding to xylans ( $\beta$-D-xylopyranoside) were apparent for $\mathrm{C}_{2}-\mathrm{H}_{2}(\mathrm{X} 2), \mathrm{C}_{3}-\mathrm{H}_{3}(\mathrm{X} 3), \mathrm{C}_{4}-\mathrm{H}_{4}(\mathrm{X} 4)$, and $\mathrm{C}_{5}-\mathrm{H}_{5}$ (X5) correlations, which significantly overlaps with unassigned signals from pentose and hexose polysaccharide units, and were also less intense after IL pretreatment compare to those of the raw biomass in both WT and transgenic samples with maximum reduction observed for biomasses after $[\mathrm{TBA}][\mathrm{OH}]$ pretreatment. Apart from these, signals from $\mathrm{C}_{4}-\mathrm{H}_{4}$ correlations of 4-O-methyl- $\alpha$-D-glucuronic acid (U4) were also observed in some samples; these units are either well cleaved or 'disappear' with their attached xylan units under the various IL pretreatments.

In summary, none of the IL pretreatments caused obviously striking structural changes to the transgenics vs. their respective WT controls. However, the alterations to the residual cell wall materials following pretreatments were substantially different for the three ILs used. As compared to the raw material, the following are notable. (1) lignins are not significantly changed except that the apparent condensation is quite substantial, and $\mathrm{PB}$ esters are efficiently cleaved from the lignin with all ILs. (2) Deacetylation is intriguingly (and hugely) different with the 3 ILs. (3) There is significantly less hemicellulose retained in both WT and transgenic samples after [TBA] $[\mathrm{OH}]$-pretreatment.

\section{Molecular weight distribution of lignin residues obtained after enzymatic saccharification}

Molecular weight distribution of solid residues isolated after enzymatic hydrolysis of poplar samples pretreated with the three ILs was measured to study the effect of zip lignin on the structural changes in the residual lignin fractions (Fig. 6). As shown, no significant differences were apparent regardless of the IL pretreatments. However, the average molecular weight of the lignin residue from the transgenic poplar was slightly higher than that from WT. For example, two distinctive peaks were found in the GPC profiles, and in the case of the [Ch][Lys]pretreated transgenic poplar, the peak around $4200 \mathrm{Da}$ was higher than that from the lower molar mass peak at $\sim 1700 \mathrm{Da}$, whereas the WT showed the opposite trend. This can be explained by the fact that more weak linkages in the transgenic poplar were cleaved during pretreatment (see Table 2) and the fragments (because of the produced acid groups) were more soluble in the solvent (i.e., the lignins required less depolymerize to dissolve from the wall), whereas the more stable bonds remained. Table 2 shows the lignin content after IL pretreatments. As shown in Table 2, significant amount of lignin was removed after IL pretreatment, especially when pretreated with [Ch][Lys]. Lignin removals from Line 5 were considerably higher than that from WT

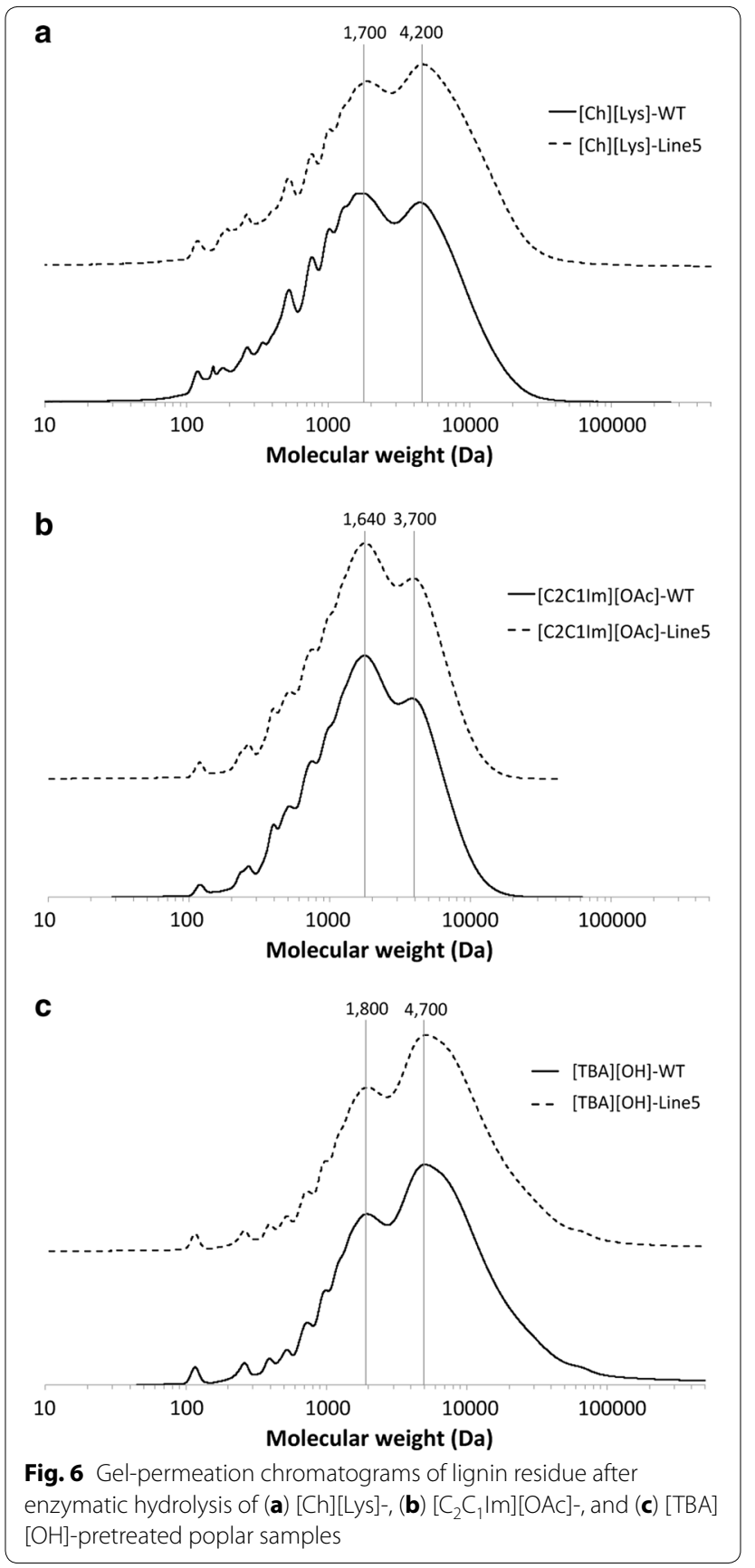


Table 2 Lignin content after IL pretreatments

\begin{tabular}{lll}
\hline & $\begin{array}{l}\text { Lignin content } \\
\text { after pretreatment (\%) }\end{array}$ & $\begin{array}{l}\text { Amount removed } \\
\text { after pretreatment (\%) }\end{array}$ \\
\hline Raw [4] & & \\
WT & 20.2 & - \\
Line 5 & 21.6 & - \\
[Ch][Lys] & & \\
WT & 10.6 & 47.6 \\
Line 5 & 7.9 & 63.4 \\
[C $C_{1}$ Im] $[O A c]$ & & \\
WT & 14.9 & 26.4 \\
Line 5 & 12.0 & 44.4 \\
[TBA][OH] & & \\
WT & 18.0 & 10.7 \\
Line 5 & 16.5 & 23.7 \\
\hline
\end{tabular}

regardless of IL used. These profiles likely illustrate the higher average molecular weight of lignin residue after enzymatic saccharification. In part, this is because the ferulates can actually participate in a greater variety of intractable linkages, while at the same time, introducing the readily cleavable ester bonds into the lignin backbone [4].

When a comparison is made between three IL pretreatments, the average molecular weight of the solid residue was in the following order: $[\mathrm{TBA}][\mathrm{OH}] \gg[\mathrm{Ch}]$ [Lys $]>\left[\mathrm{C}_{2} \mathrm{C}_{1} \mathrm{Im}\right][\mathrm{OAc}]$ in both WT and transgenic poplars. As previously discussed, both $\left[\mathrm{C}_{2} \mathrm{C}_{1} \mathrm{Im}\right][\mathrm{OAc}]$ and [Ch][Lys] are highly capable of lignin removal during the pretreatment process $[15,20,21,33]$. In addition, a higher pretreatment temperature is employed for these two ILs (compared to [TBA] [OH]), and these conditions could be responsible for enhanced degradation of the lignin structure.

\section{Discussion}

There have been many efforts to alter cell wall lignin content and composition in attempts to improve lignocellulosic biomass processing efficiency. Herein, we report on the IL pretreatment of engineered poplar lines in which monolignol ferulate conjugates were incorporated into lignins using a xylem-specific CesA 8 promoter driving an exotic FMT gene from Chinese angelica (Angelica sinensis) [4]. As previously reported, the contents of lignin in both WT and transgenic lines were not significantly different [4]. However, the amount of ML-FA conjugate in the lignins of transgenic poplars was higher (up to 13 times) than in WT, indicating that transgenic poplar lines have more chemically labile backbone linkages. Compositional analysis of IL-pretreated poplars resulted in lowered residual lignin contents from the transgenic poplar lines (see Additional file 1). Regardless of the
ILs employed, the transgenic poplar lines consistently showed substantial improvements in saccharification yield after pretreatment. This indicates that increased sugar yield under limited-release conditions is correlated with lignin removal after IL pretreatment. [Ch][Lys] showed the highest improvement. [Ch][Lys] is known for its ability to dissolve lignin that can be removed from the materials to be saccharified by precipitation upon addition of an anti-solvent following the pretreatment step. ILs containing [Lys $^{-}$anions, with their strong hydrogen bond basicity, have been found to provide an excellent delignification [15].

Although the glucose yield after enzymatic saccharification of $\left[\mathrm{C}_{2} \mathrm{C}_{1} \mathrm{Im}\right][\mathrm{OAc}]$-pretreated poplar was lower in the transgenic lines compared to that from [Ch] [Lys] pretreated samples, its pretreatment efficacy has been well established [13, 20, 34, 35]. In general, $\left[\mathrm{C}_{2} \mathrm{C}_{1} \mathrm{Im}\right][\mathrm{OAc}]$ pretreatment results in the disruption of inter- and intramolecular hydrogen bonding between cellulose fibrils and lignin, resulting in solubilization of the biomass cell wall and substantially improving the pretreatment efficacy [13]. When pretreated with [TBA] $[\mathrm{OH}]$, the yield of fermentable sugar was relatively low ( 30\%) compared to the other two ILs. Lower sugar yield could be attributed to the following: (1) some ILs have specific interactions with biomass, and those interactions are dependent on the cation, anion, temperature, and time used in the pretreatment step and (2) the extent and degree of biomass recalcitrance varies as a function of the biomass itself [2].

Overall, the strategic introduction of ester bonds into the lignin backbone in poplar produced biomass that can be processed more readily by IL treatments. This is a quite pleasing result as IL-base pretreatments are relatively biomass-agnostic; significant differences are expected for pretreatments that fare poorly for woody biomass, such as the ammonia-based processes, but apparently even processes such as IL pretreatment can benefit from the structural changes introduced into these transgenics. Among the transgenic lines, those with relatively high ML-FA conjugate levels in their lignins showed the highest digestibility. Equally important, the wood derived from the transgenic poplar requires lower chemical dosage and energy inputs for the production of fermentable sugars, which could improve the economic viability of ethanol production as well as biomass-derived value-added chemicals.

\section{Conclusions}

The development of engineered biomass with reduced recalcitrance is a key technology that could improve the efficiency and viability of the next-generation biofuels. In this work, transgenic poplar that contains zip lignins, monolignol ferulate conjugate-derived units, was 
pretreated with ILs. The strategic introduction of ester bonds into the lignin backbone resulted in increased pretreatment efficiency and released more carbohydrates with lower energy input. The transgenic poplar lines showed higher levels of monomeric sugar release compared to the WT when treated with three different ILs and followed by enzymatic saccharification. These results clearly indicate that altering the natural lignification processes and taking advantage of its inherent plasticity has the potential to improve biomass conversion to liquid fuels. Combined with the development of lignocellulosic biomass streams that are more amenable to chemical depolymerization, IL pretreatment of biomass for enhanced biofuels production could facilitate a means to develop an economically viable and sustainable biofuel industry.

\section{Additional file}

Additional file 1: Figure S1. Mass balances during three different IL pretreatments followed by enzymatic hydrolysis.

\begin{abstract}
Abbreviations
WT: wild type; IL: ionic liquid; ML-FA: monolignol ferulate; COMT: caffeic acid 3-O-methyltransferase; CCR: cinnamoyl-CoA reductase; FMT: feruloyl-CoA monolignol transferase; DI water: deionized water; HPLC: high-performance liquid chromatography; RI: refractive index; GPC: gel permeation chromatography; 2D: two-dimensional; HSQC: heteronuclear single-quantum coherence; ANOVA: analysis of variance.
\end{abstract}

\begin{abstract}
Authors' contributions
KK performed the pretreatment experiments and overall data analysis. TD performed NMR analysis. SS supervised the overall experiments. SS, JR, SM, and BS coordinated the collaborative project, contributed to the original experimental design, and analyzed the results. SM produced the transgenic poplars that were prepared and analyzed in the lab of JR. KK and TD drafted the manuscript. All authors read and approved the final manuscript.
\end{abstract}

\section{Author details}

${ }^{1}$ Deconstruction Division, Joint BioEnergy Institute, Emeryville, CA, USA. ${ }^{2}$ Biological and Engineering Sciences Center, Sandia National Laboratories, 7011 East Avenue, Livermore, CA 94551, USA. ${ }^{3}$ Department of Biochemistry, University of Wisconsin, Madison, WI, USA. ${ }^{4}$ Department of Energy Great Lakes Bioenergy Research Center, Wisconsin Energy Institute, Madison, WI, USA. ${ }^{5}$ Department of Wood Science, University of British Columbia, Vancouver, Canada. ${ }^{6}$ Biological and Engineering Sciences Division, Lawrence Berkeley National Laboratory, Berkeley, CA, USA.

\section{Acknowledgements}

The authors would like to thank Jian Sun of the Joint BioEnergy Institute for valuable discussions, and Dr. Steven Karlen of the Great Lakes Bioenergy Research Center for preparing the wood samples.

\section{Competing interests}

The authors declare that they have no competing interests.

\section{Availability of data and materials}

All data supporting the conclusions of this article are included within the manuscript.

\section{Consent for publication}

All authors agreed to publish this article.

\section{Funding}

This work was part of the DOE Joint BioEnergy Institute (http://www.jbei.org) supported by the US Department of Energy, Office of Science, Office of Biological and Environmental Research, through contract DE-AC02-05CH11231 between Lawrence Berkeley National Laboratory and the U.S. Department of Energy. JR and SDM were funded by the DOE Great Lakes Bioenergy Research Center (DOE BER Office of Science DE-FC02-07ER64494).

\section{Publisher's Note}

Springer Nature remains neutral with regard to jurisdictional claims in published maps and institutional affiliations.

Received: 19 January 2017 Accepted: 11 April 2017

Published online: 20 April 2017

\section{References}

1. Simmons BA, Loque D, Blanch HW. Next-generation biomass feedstocks for biofuel production. Genome Biol. 2008;9(12):242.

2. Li CL, Knierim B, Manisseri C, Arora R, Scheller HV, Auer M, et al. Comparison of dilute acid and ionic liquid pretreatment of switchgrass: biomass recalcitrance, delignification and enzymatic saccharification. Bioresour Technol. 2010:101(13):4900-6.

3. Lynd LR. Overview and evaluation of fuel ethanol from cellulosic biomass: technology, economics, the environment, and policy. Annu Rev Energ Env. 1996;21:403-65.

4. Wilkerson CG, Mansfield SD, Lu F, Withers S, Park JY, Karlen SD, et al. Monolignol ferulate transferase introduces chemically labile linkages into the lignin backbone. Science. 2014;344(6179):90-3.

5. Vanholme R, Cesarino I, Rataj K, Xiao YG, Sundin L, Goeminne G, et al. Caffeoyl shikimate esterase (CSE) is an enzyme in the lignin biosynthetic pathway in arabidopsis. Science. 2013;341(6150):1103-6.

6. Wang HZ, Xue YX, Chen YJ, Li RF, Wei JH. Lignin modification improves the biofuel production potential in transgenic Populus tomentosa. Ind Crop Prod. 2012;37(1):170-7.

7. Fu CX, Mielenz JR, Xiao XR, Ge YX, Hamilton CY, Rodriguez M, et al. Genetic manipulation of lignin reduces recalcitrance and improves ethanol production from switchgrass. Proc Natl Acad Sci USA. 2011;108(9):3803-8.

8. Van Acker R, Leple JC, Aerts D, Storme V, Goeminne G, Ivens B, et al. Improved saccharification and ethanol yield from field-grown transgenic poplar deficient in cinnamoyl-CoA reductase. Proc Natl Acad Sci USA. 2014;111(2):845-50.

9. Scullin C, Cruz AG, Chuang YD, Simmons BA, Loque D, Singh S. Restricting lignin and enhancing sugar deposition in secondary cell walls enhances monomeric sugar release after low temperature ionic liquid pretreatment. Biotechnol Biofuels. 2015;8:95.

10. Moniruzzaman M, Nakashima K, Kamiya N, Goto M. Recent advances of enzymatic reactions in ionic liquids. Biochem Eng J. 2010;48(3):295-314.

11. Ibrahim F, Moniruzzarnan M, Yusup S, Uemura Y. Dissolution of cellulose with ionic liquid in pressurized cell. J Mol Liq. 2015;211:370-2.

12. Singh $S$, Cheng G, Sathitsuksanoh N, Wu D, Varanasi P, George A, et al. Comparison of different biomass pretreatment techniques and their impact on chemistry and structure. Front Energy Res. 2015;2:62.

13. Singh S, Simmons BA, Vogel KP. Visualization of biomass solubilization and cellulose regeneration during ionic liquid pretreatment of switchgrass. Biotechnol Bioeng. 2009;104(1):68-75.

14. Brandt A, Grasvik J, Hallett JP, Welton T. Deconstruction of lignocellulosic biomass with ionic liquids. Green Chem. 2013;15(3):550-83.

15. Sun N, Parthasarathi R, Socha AM, Shi J, Zhang S, Stavila V, et al. Understanding pretreatment efficacy of four cholinium and imidazolium ionic liquids by chemistry and computation. Green Chem. 2014;16(5):2546-57.

16. Hou XD, Smith TJ, Li N, Zong MH. Novel renewable ionic liquids as highly effective solvents for pretreatment of rice straw biomass by selective removal of lignin. Biotechnol Bioeng. 2012;109(10):2484-93.

17. Hou XD, Xu J, Li N, Zong MH. Effect of anion structures on cholinium ionic liquids pretreatment of rice straw and the subsequent enzymatic hydrolysis. Biotechnol Bioeng. 2015;112(1):65-73. 
18. Xu F, Sun J, Konda NM, Shi J, Dutta T, Scown CD, et al. Transforming biomass conversion with ionic liquids: process intensification and the development of a high-gravity, one-pot process for the production of cellulosic ethanol. Energy Environ Sci. 2016;9(3):1042-9.

19. Parthasarathi R, Sun J, Dutta T, Sun N, Pattathil S, Konda NM, et al. Activation of lignocellulosic biomass for higher sugar yields using aqueous ionic liquid at low severity process conditions. Biotechnol Biofuels. 2016;9(1):1.

20. Cheng G, Varanasi P, Arora R, Stavila V, Simmons BA, Kent MS, et al. Impact of ionic liquid pretreatment conditions on cellulose crystalline structure using 1-ethyl-3-methylimidazolium acetate. J Phys Chem B. 2012;116(33):10049-54.

21. Shi J, Balamurugan K, Parthasarathi R, Sathitsuksanoh N, Zhang S, Stavila $V$, et al. Understanding the role of water during ionic liquid pretreatment of lignocellulose: co-solvent or anti-solvent? Green Chem. 2014;16(8):3830-40.

22. Sluiter A, Hames B, Ruiz R, Scarlata C, Sluiter J, Templeton D, et al. Determination of structural carbohydrates and lignin in biomass - laboratory analytical procedure (LAP). National Renewable Energy Laboratory. Report number TP-510-42618. 2008. https://www.nrel.gov/bioenergy/ biomass-compositional-analysis.html

23. Sadeghifar H, Cui C, Argyropoulos DS. Toward thermoplastic lignin polymers. Part 1. Selective masking of phenolic hydroxyl groups in kraft lignins via methylation and oxypropylation chemistries. Ind Eng Chem Res. 2012;51(51):16713-20.

24. Kim H, Ralph J. Solution-state $2 D$ NMR of ball-milled plant cell wall gels in DMSO-d(6)/pyridine-d(5). Org Biomol Chem. 2010;8(3):576-91.

25. Mansfield SD, Kim H, Lu FC, Ralph J. Whole plant cell wall characterization using solution-state 2D NMR. Nat Protoc. 2012;7(9):1579-89.

26. Rencoret J, Gutierrez A, Nieto L, Jimenez-Barbero J, Faulds CB, Kim H, et al. Lignin composition and structure in young versus adult eucalyptus globulus plants. Plant Physiol. 2011;155(2):667-82.
27. Karlen SD, Zhang C, Peck ML, Smith RA, Padmakshan D, Helmich KE, et al. Monolignol ferulate conjugates are naturally incorporated into plant lignins. Sci Adv. 2016;2(10):e1600393.

28. Uppugundla N, Sousa LD, Chundawat SPS, Yu XR, Simmons B, Singh $S$, et al. A comparative study of ethanol production using dilute acid, ionic liquid and AFEX (TM) pretreated corn stover. Biotechnol Biofuels. 2014;7:72.

29. Mazza M, Catana DA, Vaca-Garcia C, Cecutti C. Influence of water on the dissolution of cellulose in selected ionic liquids. Cellulose. 2009;16(2):207-15.

30. Abe M, Fukaya Y, Ohno H. Fast and facile dissolution of cellulose with tetrabutylphosphonium hydroxide containing $40 \mathrm{wt} \%$ water. Chem Commun. 2012;48(12):1808-10.

31. Stewart JJ, Akiyama T, Chapple C, Ralph J, Mansfield SD. The effects on lignin structure of overexpression of ferulate 5-hydroxylase in hybrid poplar. Plant Physiol. 2009;150(2):621-35.

32. Stewart JJ, Kadla JF, Mansfield SD. The influence of lignin chemistry and ultrastructure on the pulping efficiency of clonal aspen (Populus tremuloides Michx.). Holzforschung. 2006;60(2):111-22.

33. Hou XD, Li N, Zong MH. Facile and simple pretreatment of sugar cane bagasse without size reduction using renewable ionic liquids-water mixtures. Acs Sustain Chem Eng. 2013;1(5):519-26.

34. Uppugundla N, da Costa Sousa L, Chundawat SP, Yu X, Simmons B, Singh $\mathrm{S}$, et al. A comparative study of ethanol production using dilute acid, ionic liquid and AFEX ${ }^{\mathrm{TM}}$ pretreated corn stover. Biotechnol Biofuels. 2014;7(1):1.

35. Li Q, He Y-C, Xian M, Jun G, Xu X, Yang J-M, et al. Improving enzymatic hydrolysis of wheat straw using ionic liquid 1-ethyl-3-methyl imidazolium diethyl phosphate pretreatment. Bioresour Technol. 2009;100(14):3570-5.

\section{Submit your next manuscript to BioMed Central and we will help you at every step:}

- We accept pre-submission inquiries

- Our selector tool helps you to find the most relevant journal

- We provide round the clock customer support

- Convenient online submission

- Thorough peer review

- Inclusion in PubMed and all major indexing services

- Maximum visibility for your research

Submit your manuscript at www.biomedcentral.com/submit
() BioMed Central 